\title{
Macroscopic Description of Small and Large Intestine of the Sloth Bradypus variegatus
}

\author{
Lucilo Bioni da Fonseca Filho, Priscilla Virgínio de Albuquerque, Silvia Fernanda de Alcântara, \\ Júlio Cézar dos Santos Nascimento, Maria Eduarda Luiz Coelho de Miranda, Gilcifran Prestes de Andrade, \\ Lourival Barros de Sousa Brito Pereira, Fernanda Barreto Afonso Menezes, \\ Emanuela Polimeni de Mesquita \& Marleyne José Afonso Accioly Lins Amorim
}

\begin{abstract}
Background: Sloths of the species Bradypus variegatus are mammals with peculiar habits, which feed mostly young leaves of 'embaúba' and occur broadly in Central and South America. This specie has the greatest occurrence in Brazilian Northeast, making it a biological model for several researches in the fields as anatomy, physiology, genetics, pathology, histology and ecology, which provide data to literature in order to benefit maintenance and preservation of these animals. This study aimed to describe unpublished data about small and large intestine anatomy of the sloth Bradypus variegatus, in order to collaborate for knowledge of its digestive processes.

Materials, Methods \& Results: In order to perform this present research, 10 corpses of specie Bradypus variegatus belonged to the acquis of Anatomy Division, Department of Animal Morphology and Physiology (DMFA); Federal Rural University of Pernambuco (UFRPE), with 5 males and 5 females, the study was authorized by Animal Use and Experimentation Ethic Committee license (CEUA-UFRPE), nº 034/2015. All 10 animals used had natural death, were obtained through a donation of CETAS Tangará (Centro de Triagem de Animais Silvestres - Wildlife Screening Center), and located in the city of Recife. Animals were dissected at abdominal and pelvic portion, from a median sagittal incision, followed by lateral folding of skin, muscle and withdrawal of pubis portion for exposition and description of intestines, with analysis of syntopy and measurement of these organs. A relation was observed among external holes of urinary, reproductive and digestive systems. A relation was still observed among intestines and stomach, liver, kidneys, bladder and abdominal cavity wall. Some animals had absence of sigmoid colon, ventral and dorsal descendent colon. Regarding measurement, small intestine ranged from 147.09 to $163.59 \mathrm{~cm}$ for males and 117.44 to $151.28 \mathrm{~cm}$ for females, while large intestine varied between 39.68 and $43.35 \mathrm{~cm}$ for males, and 33.19 and $44.47 \mathrm{~cm}$ for females. Urinary and reproductive systems had a same external hole at perineal portion for both gender. Whereas digestive system ended at anus as occur commonly among mammals.

Discussion: Among specimens described, most had the same anatomic profile regarding the intestinal portions and syntopy performed over other abdominal cavity organs. A difference was observed on liver size, increment of $20 \%$ for females and males sampled, excluding animals that had absence of structure that were minority, once $40 \%$ of females had no ventral descending colon, $20 \%$ of males and females had no sigmoid colon, and $20 \%$ of males had no dorsal descending colon. However, some animals that had absence demonstrated increase of other adjacent structures, for example, male that had no dorsal descending colon developed the largest sigmoid colon observed among animals measured for portions of duodenum, ventral descending colon, ascending colon and dorsal descending colon. Regarding the measurement of small and large intestine, Bradypus variegatus had differences compared to other herbivores, what suggests that this fact is associated to a restricted diet, in which that animal is submitted. Because of literature shortage about digestive system of specie Bradypus variegatus and other species of wild animals in general, it still difficult to infer or plot more accurate affirmations about this subject.
\end{abstract}

Keywords: Bradypus variegatus, macroscopic description, small and large intestine. 


\section{INTRODUCTION}

Sloths have arboreal habit, mainly fed young or mature leaves, flowers, green branch and fruits. These animals usually have low water intake, which it is restrict to water from leaves and fruit consumed $[6,8]$. Compared to carnivores, herbivores consume a diet of lower nutritive value and digestibility, which directly affect intestine size, then promoting a longer intestine [9]. Thus, this country detached by presenting the greatest natural reserve of Bradypodidae animals, this data become important because of biologic models regarded to multidisciplinary research, which facilitate studies about anatomy, histology, physiology and pathology of these mammals [3]. The species Bradypus variegatus is typical of Neotropical region and present the greatest geographic distribution across sloths, occurring from Honduras to North Argentina, also commonly found in Brazilian Northeast $[1,7,13]$

Before deficiency of literature about wild animals and necessity of knowledge about sloth $B$. variegatus, by merit of their great occurrence in Brazil and impact that they suffer, observing species sensibility and environment degradation caused by human actions, our study intend to perform a anatomic description of small and large intestine of the Xenarthras, delimiting their portions and describing the syntopy based on anatomic quadrant of abdominal region common to mammals. Also, analyze the length of these organs and relations across external holes of urinary, reproductive and digestive systems, in order to contribute to understand the digestive process of this species in matter, supporting their conservation.

\section{MATERIALS AND METHODS}

\section{Location and animals}

In order to perform this study, we used 10 adult sloths of species $B$. variegatus (5 males and 5 females) belonging to the acquis of Morphology and Physiology Department, Anatomy Division, Federal Rural University of Pernambuco (DMFA/UFRPE). Animals were fixed with $20 \%$ formaldehyde and kept in a pool with $30 \%$ saline solution.

\section{Methodology}

The 10 specimens were dissected on abdominal and pelvic region with a median sagittal incision followed by fold of skin, muscle, generation of lateral windows and withdrawal of pubis portion for a detailed macroscopic analysis in intestines. After that, all portions of small and large were described, identifying their syntopies in each abdominal quadrant. Measurements of those portions were performed in 5 animals ( 3 females and 2 males) using a tape to obtain ex situ measure of jejunum-ileum intestine and a steel caliper ruler to measure duodenum and in situ parts of large intestine. After measurements, pipes that open in external holes of urinary, reproductive and digestive systems were dissected for identification of the relation among them.

\section{RESULTS}

According to intestine identification and their syntopies, it was organized as measurement of organs; and checking the relations among external holes of urinary, reproductive and digestive systems of the Bradypodidae sampled.

\section{Identification and syntopy intestine portions}

Duodenum is located on right hypochondriac and epigastric region, with initial portion located in epigastrium, then transversely follows at hypochondrium with duodenal flexure. This first portion present on epigastrium is related ventrally and cranially with stomach, dorsally with liver and caudally with jejunum-ileum folds. Hypochondrium has ventral relation to stomach, dorsal to liver, cranial to stomach, and liver and caudal to jejunum-ileum folds. In $20 \%$ of females and $20 \%$ of males, the liver had a larger size, which culminated in its cranial and dorsal relation to duodenum.

Jejunum-ileum loops are distributed in the hypochondriac, right side and umbilical regions. In the hypochondrium, they are related ventrally to stomach, dorsally to liver, cranially to duodenum, and caudally remains on right side quadrant. In this region, loops surround the ascending colon of large intestine, and present ventral syntopy to abdomen wall, dorsal to the right kidney and abdomen wall, cranial to the sigmoid colon and jejunum-ileum loops of the right and caudal hypochondrium to the abdominal cavity wall. In the umbilical region, there is a ventral relation to the bladder and abdomen wall, dorsal to the ventral transverse colon, cranial to stomach, and caudal to bladder, gonads and rectum.

In $20 \%$ of males, the jejunum-ileum intestine had your final portion on left side quadrant, which related ventrally and caudally to the abdomen wall, dorsally to the left kidney and abdomen wall, and cranially to the descending ventral colon. 
Large intestine got started on left side quadrant, with cecum in comma shape ventrally connected to jejunal-ileal loops and abdomen wall, dorsally to abdomen wall and left kidney, cranially to stomach, and caudally to abdomen cavity wall.

Cecum still follows descendant ventral colon on the left side quadrant. This colon is located ventral to jejunal-ileal loops and left kidney, dorsal to stomach and abdomen wall, cranial to jejunal-ileal loops, bladder abdomen wall, and caudal to pylorus. However, its absent was detected in $40 \%$ of females. Once present, keeps on umbilical quadrant with the transverse ventral colon, which has ventral relation to jejunum-ileum loops, bladder and abdomen wall, dorsal to rectum and dorsal flexure of sigmoid colon, cranial to ventral flexure of sigmoid colon and stomach, and caudal to gonads, rectum and jejunal-ileal loops. In cases where had no descendant ventral colon, the cecum kept with the transverse ventral colon, which in all specimens sampled, was succeed by ascending colon in the right side region.

The ascending colon ventrally related to abdomen wall, dorsally to jejunal-ileal loops and right kidney, cranially to jejunal-ileal loops, and caudally to abdomen wall. Also presents continuity to sigmoid colon on umbilical quadrant, which is split in right side flexure, ventral flexure, medium portion, and dorsal flexure. The right side flexure has ventral syntopy to abdomen wall, dorsal to transverse ventral colon, cranial to stomach, and caudal to transverse ventral colon. Ventral flexure is dorsal to stomach and jejunal-ileal loops, caudal to pylorus, and ventral and cranial to jejunal-ileal loops. Medium portion is positioned ventral and cranial to jejunal-ileal loops, dorsal to stomach, and caudal to pylorus. Dorsal flexure ventrally connects to stomach, cranial and dorsally to pylorus, and caudally is followed by descendant dorsal colon, which has ventral relation to stomach and abdomen wall, dorsal to abdomen wall and loops, cranial to previous pylorus, loops and succeed by rectum. Sigmoid colon was absent in $20 \%$ of males and females, which the ascending colon follows the descendant dorsal colon. This colon was not detected in $20 \%$ of males, in which the sigmoid colon directly follow in rectum.

Rectum is located on umbilical and hypogastric region. In the first region, rectum has ventral relation to transverse ventral colon, gonads and bladder, dorsal to abdomen wall, cranial to descendant colon, and caudally keep on hypogastric, where has ventral relation to final portion of bladder, ureter and gonads, dorsal to pelvis wall, and caudally is linked to outside through anus.

In Figure 1, there is an identification of intestinal portion from sloth, inclusive with demonstration of variations analyzed for specimens sampled.

\section{Measurement of intestinal portions}

Regarding the small intestine length, duodenum ranged from 2.59 to $3.09 \mathrm{~cm}$ for males and 3.44 to $4.70 \mathrm{~cm}$ for females. Whereas, jejunum-ileum had lengths between 144 and $161 \mathrm{~cm}$ for males, and 114 and $147 \mathrm{~cm}$ for females.

For large intestine, the extension of its portions ranged for males and females, respectively: cecum (3.26 to $4.33 \mathrm{~cm}$ and 2.87 to $4.70 \mathrm{~cm}$ ), descendant ventral colon (2.61 to $4.41 \mathrm{~cm}$ and $5.56 \mathrm{~cm}$ ), transverse colon (6.61 to $6.69 \mathrm{~cm}$ and 5.73 to $12.08 \mathrm{~cm}$ ), ascending colon (5.44 to $7.21 \mathrm{~cm}$ and 4.74 to 7.34 $\mathrm{cm})$, sigmoid colon $(10.96 \mathrm{~cm}$ and 4.21 to $4.91 \mathrm{~cm})$, descendant dorsal colon (7.61 and 5.41 to $7.34 \mathrm{~cm})$, and rectum (11.60 to $12.90 \mathrm{~cm}$ and 8.40 to $12.2 \mathrm{~cm}$ ).

Results of intestinal portions measurements are detailed on Table 1.

Table 1. Measurement in centimeter of intestinal portion lengths from sloths Bradypus variegatus.

\begin{tabular}{cccccccccc}
\hline Animal & Duodenum & $\begin{array}{c}\text { Jejunal-Ileal } \\
\text { Intestine }\end{array}$ & Cecum & $\begin{array}{c}\text { Descending } \\
\text { Ventral Colon }\end{array}$ & $\begin{array}{c}\text { Transverse } \\
\text { Colon }\end{array}$ & $\begin{array}{c}\text { Ascending } \\
\text { Colon }\end{array}$ & $\begin{array}{c}\text { Sigmoid } \\
\text { Colon }\end{array}$ & $\begin{array}{c}\text { Descending } \\
\text { Dorsal Colon }\end{array}$ & Rectum \\
\hline F1 & 4.70 & 116 & 2.87 & 5.56 & 9.23 & 7.34 & - & 7.34 & 12 \\
F2 & 4.28 & 147 & 3.76 & - & 12.08 & 5.31 & 4.91 & 6.21 & 12.2 \\
F3 & 3.44 & 114 & 4.70 & - & 5.73 & 4.74 & 4.21 & 5.41 & 8.40 \\
M1 & 2.59 & 161 & 3.26 & 2.61 & 6.69 & 7.21 & - & 7.01 & 12.90 \\
M2 & 3.09 & 144 & 4.33 & 4.41 & 6.61 & 5.44 & 10.96 & - & 11.6 \\
\hline
\end{tabular}




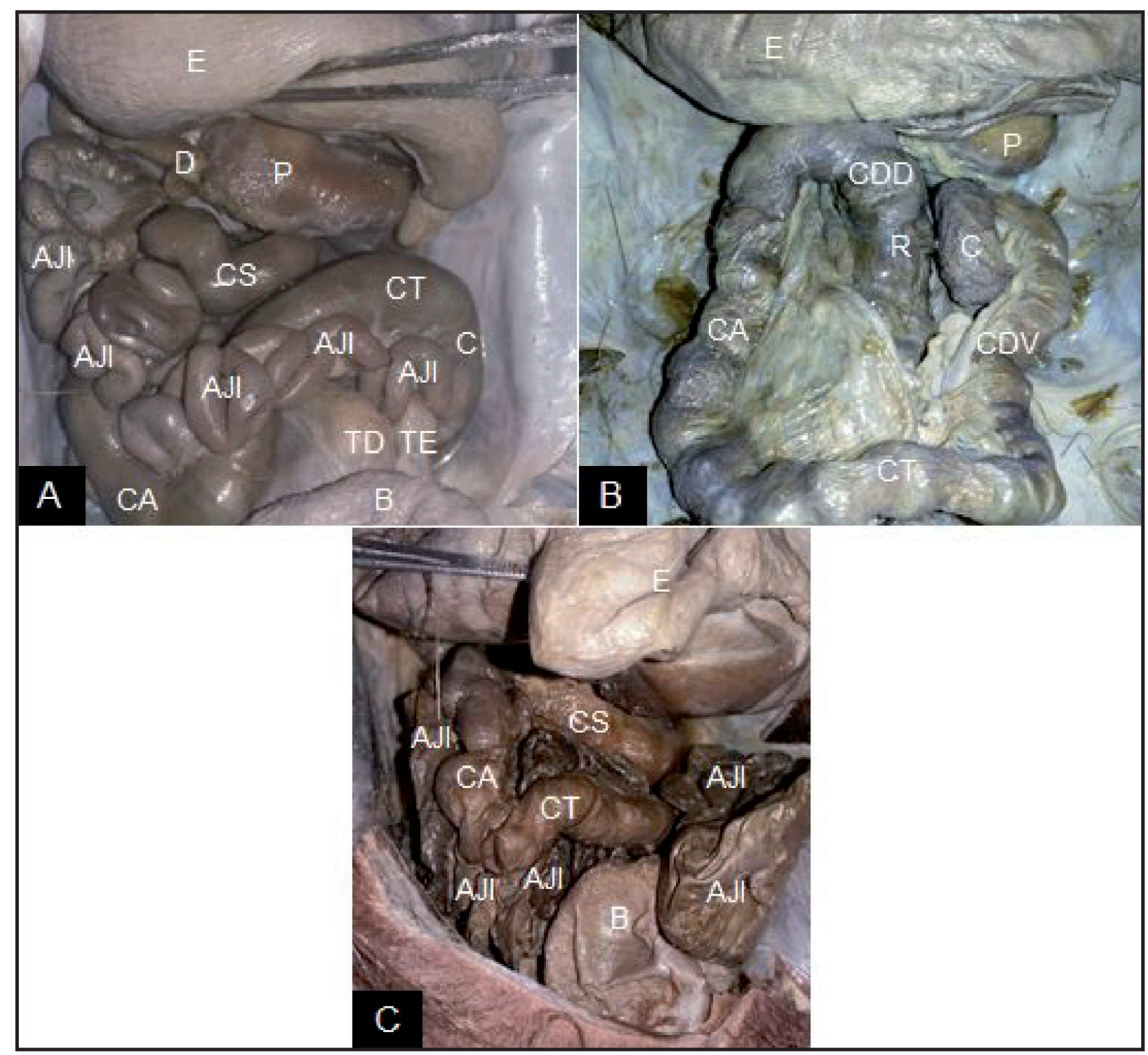

Figure 1. Macroscopy of abdominal organs from sloth Bradypus variegatus, with identification of the intestinal portions. A- Animal with absence of the descendant ventral colon. B- Animal with absence of sigmoid colon. C- Animal without descendant dorsal colon. $[\mathrm{E}=\mathrm{Stomach} ; \mathrm{P}=\mathrm{Pylorus} ; \mathrm{D}=$ Duodenum; AJI = Jejunal-ileal loops; $\mathrm{C}=\mathrm{Cecum} ; \mathrm{CDV}=$ Descending ventral colon, $\mathrm{CT}=$ Transverse colon; $\mathrm{CA}=\mathrm{Ascending}$ colon; $\mathrm{CS}=\mathrm{Sigmoid}$ colon; CDD: Descending dorsal colon; $\mathrm{R}=$ Rectum; $\mathrm{TD}=$ Right testicle; $\mathrm{TE}=$ Left testicle; $\mathrm{B}=$ Bladder $]$.

Relations among external holes of urinary, reproductive and digestive systems

Based on the external orifices, males repeat most general feature among mammals, with a common opening for urinary and reproductive systems, which is the external urethral ostium located at distal end of penis, whereas the orifice responsible for eliminating feces is the anus. In females, unlike most Eutheria, there is a same orifice for urinary and reproductive systems, whereas digestive system separately opens in the anus, as in males (Figure 2).

\section{DISCUSSION}

Regarding the 10 specimens sampled, most were following a pattern in relation to the intestinal portions and their syntopies in the abdominal quadrants. According to the comparison of mammals intestine that belongs to the Superorder Xenarthra, in the all species studied the duodenum was the first portion of the small intestine, which is characterized by the presence of folds and beginning of mesentery [6], this information corroborates with the results of our study, in which duodenum began in the epigastric region and 


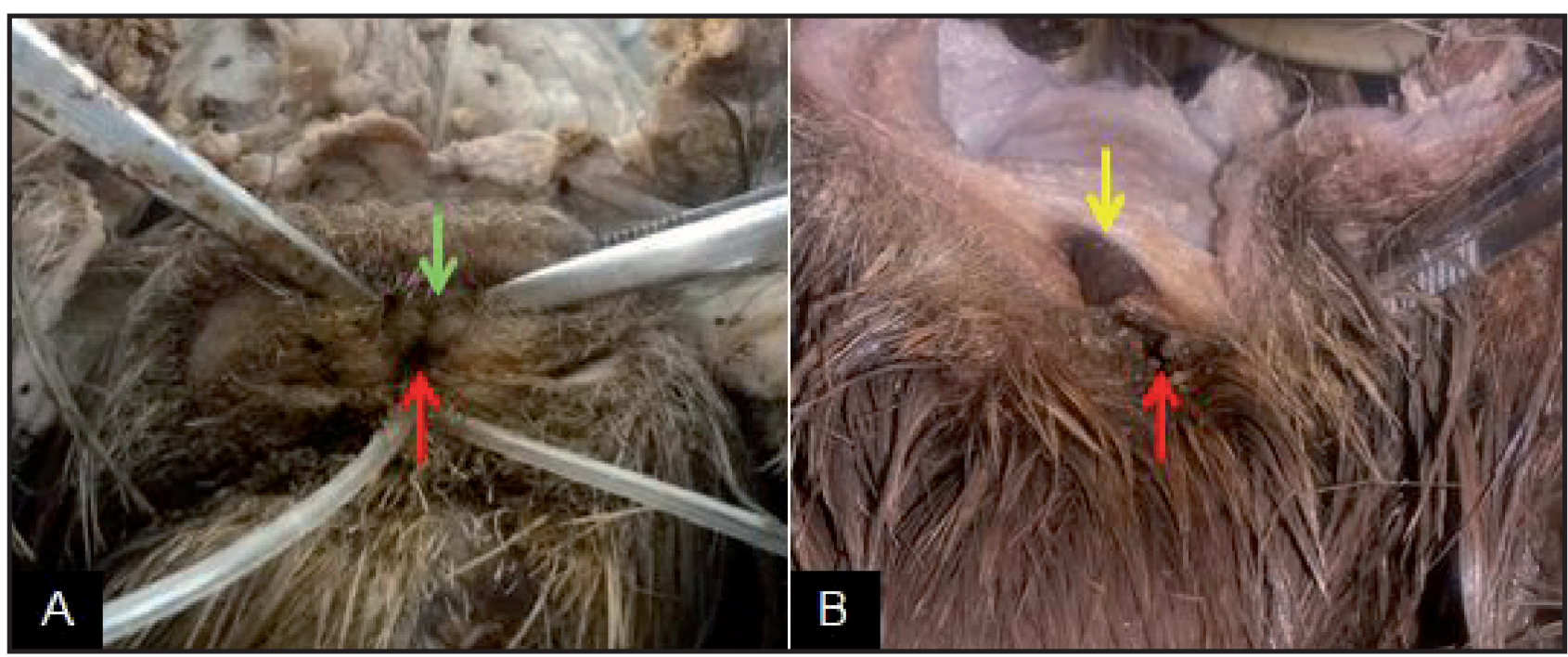

Figure 2. Identification of the external orifices of urinary, reproductive, and digestive systems in sloth Bradypus variegatus. A- Female animal. B- Male animal. $\rightarrow$ red $=$ anus; $\rightarrow$ green $=$ vulva and $\rightarrow$ yellow $=$ penis .

ended in the right hypochondrium. However, the same authors reported that sloths Bradypus torquatus had a short intestine, different from what observed in $B$. variegatus, with the small intestine reaching $161 \mathrm{~cm}$, which is close to the studies that reported $192 \mathrm{~cm}$ of small intestine length in Bradypodidae [10].

In two specimens of $B$. variegatus, the sigmoid colon was not detected. This absence was also reported for the species Cuniculus pacas, in which lack of the sigmoid colon is associated with a longer length of other intestine portions (cecum, ascending colon, descendant colon and rectum) [5], as well as in two specimens of this study, which had no sigmoid colon, but had the greatest extension of the ascending and descendant dorsal colon.

Comparing the measurement of intestinal segment in domestic cats, the sum of all small and large intestine portions averaged $147.24 \mathrm{~cm}$ length [6], while in sloths solely the small intestine exceeded $100 \mathrm{~cm}$. The other portions such as cecum, ascending colon, transverse colon and rectum, had lower mean values than our study, however, duodenum of the domestic cats reached results greater than Xenarthras sampled by us, averaged $9.20 \mathrm{~cm}$ length, while the sloths the greatest value observed was $4.70 \mathrm{~cm}$.

Our results for cecum measurement indicated the greatest value reaching $4.70 \mathrm{~cm}$, while in rabbits (Oryctolagus cuniculus) the results vary between 25 and $32 \mathrm{~cm}$ for cecum [2]. However, new studies reported an average of $48.19 \mathrm{~cm}$ of cecum, being $45.07 \mathrm{~cm}$ for females and $42.49 \mathrm{~cm}$ for males $[4,15]$.
In duodenum, the greatest length reported for sloths was $4.70 \mathrm{~cm}$ although, for rabbits, the mean value reported was $56.4 \mathrm{~cm}$ [15]. Total extension of small intestine also triggered discrepancy, which in our study the greatest value found was $161 \mathrm{~cm}$. However, for rabbits was reported an average of $281 \mathrm{~cm}$, being $193.87 \mathrm{~cm}$ for males and $182.95 \mathrm{~cm}$ for females [4,15]. Rectum extension solely was the greater measurement for sloths than rabbits. Thus, for Bradypodidae the greatest value measured was $12.90 \mathrm{~cm}$, and for rabbits, the results pointed an average of $7.12 \mathrm{~cm}$ [15]. Despite the herbivory, characteristic for sloths and rabbits, the results of intestinal portions reached a significant discrepancy, which indicates intestinal differences comparing animals of similar alimentary habit.

The perineal holes for male sloths are two in number, with the urinary and reproductive systems communicating with outside by the ostium in the distal end of penis, whereas the digestive system ends in the anus. For females, there is also a common orifice for urinary and reproductive systems located in the vulva, and digestive system ends in the anus, which evidenced the existence of a common space in the anus-genital region, where the penis or vulva and anus are located near a dilatation of skin that closed, resulting in a sac formation [14].

\section{CONCLUSIONS}

Regarding the identification of intestinal portions, few animals were detected with structure absence such as sigmoid colon in $20 \%$ of males and $20 \%$ of females, descending ventral colon in $40 \%$ of females 
and descending dorsal colon in $20 \%$ of males, besides a liver hypertrophy in $20 \%$ of females and males.

Regarding the size of small and large intestine, our study can conclude that the sloth $B$. variegatus has peculiarities and differences in relation to other herbivores, which should be associated with its non-general diet and low metabolism characteristic of this species.

The location of perineal orifices of males resembles the others mammals, with a common ostium to urinary and reproductive systems, present in penis and another separated for the digestive system, the anus. Females, however, differ from what is common among eutherians, and just as males, has only two perineal orifices, vulva for urinary and reproductive systems, and anus for digestive system.
The literature available needs studies that are able to clarify questions present at this work, being required more research regarding to anatomy and physiology of the species in matter.

Acknowledgements. To Anatomy Division, Department of Animal Morphology and Physiology, Federal Rural University of Pernambuco, for providing the sloth collection. To Zoo at Dois Irmãos, Recife, Pernambuco, for donating Bradypus variegatus corpses. To morphophysiology team in studies with sloths at UFRPE for supporting and patience of the Project accomplishment.

Ethical approval. This study was approved by Animal Use Ethic Committee (CEUA-UFRPE) license $n^{\circ}$ 034/2015.

Declaration of interest. The authors report no conflicts of interest. The authors alone are responsible for the content and writing of paper.

\section{REFERENCES}

1 Amorim M.J.A.A.L. 2000. A placenta da preguiça, Bradypus variegatus (Shinz, 1825). 78f. São Paulo, SP. Tese (Doutorado em Anatomia dos Animais Domésticos e Silvestres) - Programa de pós-graduação em Anatomia dos Animais Domésticos e Silvestres. Universidade de São Paulo.

2 Amorim M.J.A.A.L., Amorim Júnior A.A., Silva Júnior V.A., Villarouco F.M.O. \& Henrique V.V.A. 2002. Longitud total del intestino de conejos sin raza definida (Oryctolagus cuniculus). Revista Chilena de Anatomia. 20(2): 181-183.

3 Amorim M.J.A.A.L., Miglino M.A., Amorim Júnior A.A. \& Santos T.C. 2003. Aspectos morfológicos da placenta da preguiça Bradypus variegatus (Shinz, 1825). Brazilian Journal of Veterinary Research and Animal Science. 40(3): 217-226.

4 Barroso D.C., Lima A.M., Alonso L.S. \& Figueiredo M.A. 2007. Comprimento total e relativo dos diferentes segmentos do intestino de coelhos nova Zelândia. Arquivos de Ciências Veterinárias e Zoologia da Unipar. 10(2): 101-104.

5 Bürger C.P., Machado M.R.F. \& Bürger K.P. 2012. Morfologia macroscópica e topografia anatômica do intestino grosso da paca Cuniculus paca (Linnaeus, 1766). Biotemas. 25(2): 177-123.

6 Carvalho M.M., Pieri N.C.G., Pereira K.F., Lima F.C., Carniatto C.H.O., Miglino M.A., Ricci R.E. \& Martins D.S. 2014. Caracterização comparativa do intestino das espécies da Ordem Xenarthra. Pesquisa Veterinária Brasileira. 34(Supl 1): 49-56.

7 Cassano C.R. 2006. Ecologia e conservação da preguiça de coleira Bradypus torquatus (Illiger, 1811) no sul da Bahia. 106f. Dissertação (Mestrado em Zoologia) - Programa de Pós-Graduação em Zoologia, Universidade Estadual de Santa Cruz.

8 Chiarello A.G. 1998. Diet of the atlantic forest maned sloth Bradypus torquatus (Xenarthra: Bradypodidae). Journal of Zoology. 246(1): 11-19.

9 Dyce K., Sack W. \& Wensing C. 2010. Tratado de Anatomia Veterinária. 4.ed. Rio de Janeiro: Elsevier, 856p.

10 Goffart M. 1971. Function and Form in the Sloth. New York: Pergamon, 225p.

11 Larrazábal L.B. 2004. Crianza en cautiverio de perezoso de dos dedos (Choloepus didactylus). Edentata. 6: 30-36.

12 Medri I.M., Mourão G.M. \& Rodrigues F.H.G. 2011. Ordem Pilosa. In: Reis N.R., Peracchi A.L., Fregonezi M.N. \& Rossaneis B.K. (Eds). Mamíferos do Brasil: Guia de identificação. Londrina: Technical Books, pp.92-94.

13 Moraes-Barros N., Silva J.A., Miyaki C.Y. \& Morgante J.S. 2006. Comparative phylogeography of the atlantic forest endemic sloth (Bradypus torquatus) and the widespread three-toed sloth (Bradypus variegatus) (Bradypodidae, Xenarthra). Genetica. 126(1-2): 189-198.

14 Peres M.A. 2005. Colheita e avaliação do sémen do bicho-preguiça (Bradypus sp.). 74f. Tese (Doutorado em anatomia dos animais domésticos e silvestres) - Programa de Pós-graduação em anatomia dos animais domésticos e silvestres. Universidade de São Paulo. 
L.B. Fonseca Filho, P.V. Albuquerque, S.F. Alcântara, et al. 2018. Macroscopic Description of Small and Large Intestine of the Sloth Bradypus variegatus. Acta Scientiae Veterinariae. 46: 1613.

15 Quirilo M.A., Cabral V.P. \& Simonelli S. 2007. Avaliação morfométrica dos intestinos de coelhos domésticos da raça Nova Zelândia. Iniciação Científica Cesumar. 8(1): 75-81.

16 Santos A.L.Q., Menezes L.T., Kaminishi A.P.S., Leonardo T.G., Nascimento L.R., Malta T.S. \& Maximiano Neto A. 2011. Comprimentos parciais e totais de intestino de gatos domésticos Felis catus domesticus (Linnaeus, 1758). Pubvet. 5: 1086-1092.

17 Wilson D.E. \& Reeder D.M. 2005. Mammals species of the world: taxonomic and geographic reference. 3rd edn. Baltimore: The John Hopkins University, 2142p. 